\title{
Pancreatitis aguda asociada a infección por parotiditis (papera). Informe de un caso
}

\author{
Soraya López López, Carlos Marra-López Valenciano, Federico Bolado Concejo \\ Servicio de Aparato Digestivo del Complejo Hospitalario de Navarra, Pamplona. Navarra, España.
}

Acta Gastroenterol Latinoam 2020;50(2):147-149

Recibido: 23/07/2018 / Aceptado: 14/11/2018 / Publicado online: 29/06/2020

\section{Resumen}

La papera, causada por un Paramyxovirus, es una enfermedad prevenible mediante vacunación. A pesar de encontrarnos en una era en que la vacunación es universal, diversos fenómenos, como los movimientos migratorios, están condicionando un repunte en la incidencia de esta infección viral, altamente contagiosa. Presentamos el caso de una paciente con infección por parotiditis que tras 48 horas de evolución presenta dolor abdominal epigástrico intenso, transfixivo y elevación de alfa-amilasa y triacilglicerol lipasa en la analitica de sangre. Por ello, tras descartar otras etiologías más frecuentes, se diagnosticó pancreatitis aguda asociada a paperas. Este caso pone de manifiesto que, aunque es un cuadro infrecuente, la pancreatitis aguda debe ser considerada en pacientes con paperas que presenten dolor abdominal agudo. El diagnóstico precoz y el tratamiento sintomático son necesarios para prevenir y minimizar la morbimortalidad asociada a pancreatitis aguda.

Palabras claves. Parotiditis, pancreatitis, vacunas.

Correspondencia: Soraya López López

C/ Irunlarrea, 3 (CP 31008), Pamplona. Navarra, España

Tel.: 848422115

Correo electrónico: soraya.llaldcrad@gmail.com

\section{Acute pancreatitis related to mumps. A case report}

\section{Summary}

Mumps are a preventable disease by vaccination, caused by a Paramyxovirus. Even though we are in the vaccination era, different phenomena as the migratory movements, are generating a new rebound of this highly transmissible viral infection. We present a female with a severe epigastric abdominal pain and elevation of alpha-amylase and triacylglycerol lipase in blood analysis, after 48 hours of mumps infection. After the exclusion of more frequent causes, the patient was diagnosed with acute pancreatitis related to mumps. This case shows that, despite it is a rare cause, acute pancreatitis should be considered in patients with mumps who present acute abdominal pain. An early diagnosis and an appropriate treatment are necessary to prevent and minimise morbi-mortality related to acute pancreatitis.

Key words. Mumps, pancreatitis, vaccines.

\section{Caso clínico}

La parotiditis, comúnmente denominada papera, es una infección viral altamente contagiosa que generalmente afecta a niños y jóvenes, prevenible mediante vacunación y causada por un Paramyxovirus. Presentamos una mujer de 19 años oriunda de Paraguay, sin antecedentes personales de interés y estado de vacunación desconocido, valorada inicialmente en el servicio de urgencias por tumefacción facial bilateral de 24 horas de evolución compatible con cuadro de parotiditis aguda. A las 48 horas acude nuevamente por dolor abdominal epigástrico, transfixivo, sin náuseas ni vómitos asociados. Refiere ausencia de trans- 
gresión dietética o alcohólica, o consumo de otros fármacos. Analíticamente destacaba elevación de alfa-amilasa 795 U/L [25-125], triacilglicerol lipasa 183 U/L [8-78] y proteína C reactiva $47,2 \mathrm{mg} / \mathrm{L}$ [0-5], sin alteración en el perfil hepático, con bilirrubina total $0,7 \mathrm{mg} / \mathrm{dL}[0,2-1,2]$, aspartato transferasa $15 \mathrm{U} / \mathrm{L}$ [5-34] y alanina transferasa $9 \mathrm{U} / \mathrm{L}$ [5-55].

Se realizó diagnóstico de parotiditis aguda mediante inmunoglobulina IgM específica para Paramyxovirus. Ecografía abdominal sin hallazgos relevantes. La paciente presentó una evolución favorable, se reintrodujo dieta oral con buena respuesta, y fue dada de alta tras 48 horas, con diagnóstico de pancreatitis aguda leve asociada a infección aguda por parotiditis.

\section{Discusión}

Las complicaciones de las paperas incluyen orquitis, epididimitis, meningitis y pancreatitis. ${ }^{1} \mathrm{La}$ pancreatitis aguda, una de las causas más frecuentes de ingreso hospitalario en los servicios de gastroenterología, es un proceso inflamatorio del páncreas con afectación variable de otros tejidos y órganos a distancia. ${ }^{2}$

En los últimos años se ha observado un aumento de su incidencia, estimándose alrededor de 5-11 casos por 100.000 habitantes. ${ }^{3}$ Para su diagnóstico se requieren dos de los siguientes tres criterios: 1) cuadro clínico típico (dolor abdominal epigástrico-hipocondrio izquierdo con irradiación transfixiva), 2) hallazgos radiológicos compatibles (bien por ecografía abdominal o por tomografía computarizada), 3) elevación de al menos tres veces el valor normal de alfa-amilasa y/o triacilglicerol lipasa.

En este caso, la elevación de la lipasa por debajo de tres veces su valor normal pudo deberse a la determinación de esta antes de las 24 horas del inicio del cuadro, que es cuando alcanza su pico máximo. Aproximadamente el $80 \%$ de los pacientes presentan una pancreatitis leve, y la mayoría son secundarios a patología biliar y alcohol. Alrededor del $10 \%$ son etiquetados de etiología indeterminada, tras descartar las causas más frecuentes. ${ }^{4}$

El diagnóstico etiológico es importante para proporcionar un tratamiento precoz y prevenir la recurrencia al evitar el agente causal. Otras etiologías para considerar incluyen fármacos (azatioprina, 6-mercaptopurina), drogas (cannabis), condiciones metabólicas (hipercalcemia, hipertrigliceridemia), autoinmunes, e infecciones. ${ }^{6}$

La pancreatitis aguda de etiología infecciosa es un cuadro raro cuya incidencia es difícil de estimar, ya que en muchas ocasiones se presenta como cuadros leves o incluso subclínicos. Se han descrito casos asociados al virus de la parotiditis, virus hepatotropos, coxackie, hepatitis B, citomegalovirus, varicela zóster, herpes simple, y virus de
Epstein-Barr. Otras etiologías infecciosas serían la bacteriana (mycoplasma, legionella, leptospira, salmonella), la fúngica (aspergillus) y la parasitaria (toxoplasma, cryptosporidium, ascaris). ${ }^{1}$

Presentamos un caso de pancreatitis aguda secundaria a parotiditis aguda. El primer caso descrito en la literatura fue en 1905, por Lemoine. ${ }^{1}$

La parotiditis es una enfermedad vírica contagiosa, cuyo agente etiológico más frecuente es el Paramyxovirus. La replicación viral tiene lugar en el epitelio del tracto respiratorio superior, presentando un período de incubación de entre dos y cuatro semanas. Habitualmente aparecen síntomas prodrómicos de malestar general, cefalea y/o fiebre, y posteriormente tumefacción de las glándulas salivares parótidas, típicamente bilateral. Previamente a la era vacunal se trataba de una enfermedad común en la infancia, que en ocasiones se complicaba con orquiepididimits, meningitis o pancreatitis como resultado de la afectación sistémica por la viremia. La relación temporal entre la parotiditis y la pancreatitis no está bien estableci$\mathrm{da}$, habiendo casos descritos que presentaron inicialmente pancreatitis aguda y otros en los que aparecía tras varios días de evolución de la infección vírica. ${ }^{1,7,8}$ Suele ser un cuadro autolimitado que requiere únicamente tratamiento sintomático.

El diagnóstico de confirmación de la parotiditis se obtiene mediante la detección del virus de la parotiditis en cultivo en shell-vial de células H292, tinción con anticuerpos monoclonales, reacción en cadena de la polimerasa en saliva y/o la presencia de valores de inmunoglobulina IgM específica en suero. Los casos clínicos con confirmación de laboratorio o relacionados epidemiológicamente con otro caso se consideran confirmados. En cualquier caso, se trata de una enfermedad de declaración obligatoria, tanto para casos confirmados como para casos sospechosos. ${ }^{5}$ Para el diagnóstico de la pancreatitis aguda se siguen los criterios habituales, teniendo en cuenta que en estos casos puede aparecer una elevación de amilasa secundaria a la parotiditis.

Aunque infrecuente, la pancreatitis como complicación de la parotiditis aguda debe ser tenida en cuenta en el diagnóstico diferencial etiológico, especialmente en personas con síntomas que orienten hacia este cuadro vírico, aunque estén vacunados. Es interesante señalar que en los próximos años podría verse un nuevo repunte en su incidencia, secundario a movimientos migratorios de población no vacunada y algunos colectivos no favorables a la vacunación. ${ }^{5}$ No obstante, en primer lugar, siempre deben descartarse otras causas más frecuentes de pancreatitis aguda, como la biliar, el alcohol, la hipertrigliceridemia o la hipercalcemia, entre otros. 
Este caso pone de manifiesto que la etiología infecciosa de la pancreatitis aguda debe incluirse en el diagnóstico diferencial de aquellos pacientes con clínica compatible y estudios etiológicos habituales negativos, ${ }^{6}$ especialmente la etiología vírica por ser la más común. A pesar de encontrarnos en la era vacunal, diversos fenómenos, como los movimientos migratorios, están condicionando un repunte en la incidencia de infecciones prevenibles. Por ello, aunque infrecuente, la pancreatitis aguda debe ser considerada en pacientes con paperas que presenten dolor abdominal agudo. El diagnóstico precoz y el tratamiento sintomático son necesarios para prevenir y minimizar la morbimortalidad asociada a pancreatitis aguda.

\section{Sostén financiero. Ninguno.}

\section{Referencias}

1. Parenti DM, Steinberg W, Kang P. Infectious causes of acute pancreatitis. Pancreas 1996; 13 (4): 356-371.
2. Tenner S, Baillie J, DeWitt J, Vege SS. American College of Gastroenterology Guideline: Management of Acute Pancreatitis. Am J Gastroenterol 2013; 108: 1400-1415.

3. Navarro S, Amador J, Argüello L, Ayuso C, Boadas J, De las Heras G, Farré A, Fernández-Cruz L, Ginés A, Guarner L, LópezSerrano A, Llachi J, Lluis F, De Madaria E, Martínez J, Mato R, Molero X, Oms L, Pérez- Mateo M, Vaquero E. Recomendaciones del Club Español Biliopancreático para el tratamiento de la pancreatitis aguda. Gastroenterol Hepatol 2008; 31 (6): 366-387.

4. Economou M, Zissis M. Infectious cases of acute pancreatitis. Ann Gastroenterol 2000; 13 (2): 98-101.

5. Castilla J, Fernández M, García M, Martínez V, Íñigo M, Rodrigo I, Barricarte A. Rebrote de parotiditis en la era vacunal. Factores implicados en un brote en Navarra, 2006-2007. Med Clin (Barc) 2009; 133 (20): 777- 782.

6. Rawla P, Bandaru SS, Vellipuram AR. Review of infectious etilogy of acute pancreatitis. Gastroenterol Res 2017; 10 (3): 153-158.

7. Šušković T, Vukičević-Baudoin D, Vučičević Ž, Holjevac I. Severe pancreatitis as first symptom of mumps complicated with pseudocyst and abscess of pancreas. Infection 1997; 25 (1): 39-41.

8. Atsuko T, Sakagami J, Mitsufuji S, Kataoka K. Acute pancreatitis from mumps re-infection in adulthood: a case report. J Pancreas (Online) 2008; 9 (3): 322-326. 